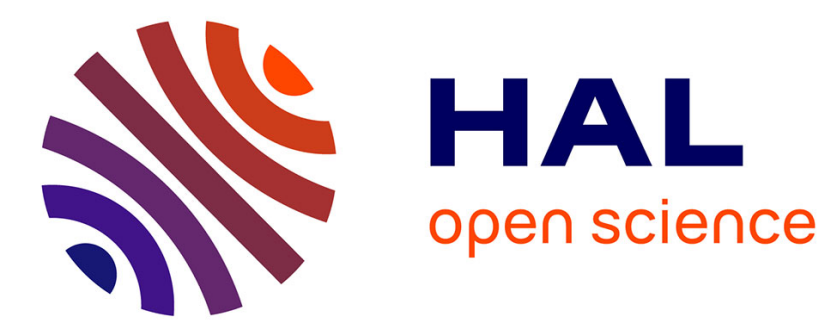

\title{
Ostracism and the Provision of a Public Good Experimental Evidence
}

\author{
Frank P. Maier-Rigaud, Peter Martinsson, Gianandrea Staffiero
}

\section{To cite this version:}

Frank P. Maier-Rigaud, Peter Martinsson, Gianandrea Staffiero. Ostracism and the Provision of a Public Good Experimental Evidence. Journal of Economic Behavior and Organization, 2009, 73 (3), pp.387. 10.1016/j.jebo.2009.11.001 . hal-00755790

\section{HAL Id: hal-00755790 https://hal.science/hal-00755790}

Submitted on 22 Nov 2012

HAL is a multi-disciplinary open access archive for the deposit and dissemination of scientific research documents, whether they are published or not. The documents may come from teaching and research institutions in France or abroad, or from public or private research centers.
L'archive ouverte pluridisciplinaire HAL, est destinée au dépôt et à la diffusion de documents scientifiques de niveau recherche, publiés ou non, émanant des établissements d'enseignement et de recherche français ou étrangers, des laboratoires publics ou privés. 


\section{Accepted Manuscript}

Title: Ostracism and the Provision of a Public Good Experimental Evidence

Authors: Frank P. Maier-Rigaud, Peter Martinsson, Gianandrea Staffiero

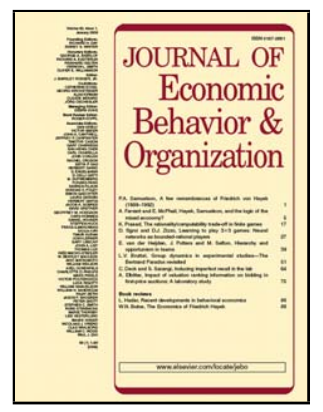

PII:

S0167-2681(09)00258-3

DOI: doi:10.1016/j.jebo.2009.11.001

Reference: JEBO 2460

To appear in: Journal of Economic Behavior \& Organization

Received date: $\quad$ 12-6-2006

Revised date: $\quad 9-11-2009$

Accepted date: $\quad 11-11-2009$

Please cite this article as: Maier-Rigaud, F.P., Martinsson, P., Staffiero, G., Ostracism and the Provision of a Public Good Experimental Evidence, Journal of Economic Behavior and Organization (2008), doi:10.1016/j.jebo.2009.11.001

This is a PDF file of an unedited manuscript that has been accepted for publication. As a service to our customers we are providing this early version of the manuscript. The manuscript will undergo copyediting, typesetting, and review of the resulting proof before it is published in its final form. Please note that during the production process errors may be discovered which could affect the content, and all legal disclaimers that apply to the journal pertain. 


\title{
Ostracism and the Provision of a Public Good Experimental Evidence ${ }^{\bullet}$
}

\author{
Frank P. Maier-Rigaud* \\ Department of Economics, University of Bonn \\ Max Planck Institute for Research on Common Goods \\ Peter Martinsson \\ Department of Economics, Göteborg University \\ Gianandrea Staffiero \\ Europe Economics \\ SP-SP Research Center - IESE Business School, University of Navarra
}

\begin{abstract}
We analyze the effects of ostracism on cooperation in a linear public good experiment with fixed partner design. Our results show that introducing ostracism increases contribution levels significantly except in first and last periods. Despite reductions in group size due to ostracism, the net effect on earnings is positive. This effect is in contrast to most alternative mechanisms aimed at increasing cooperation rates studied in the literature on public good experiments.
\end{abstract}

Keywords: Ostracism, Exclusion, Public Good, Teamwork, Experiment.

JEL Classification: C92, H41.

\footnotetext{
- We thank Martin Beckenkamp, Felix Bierbrauer, Massimo Castro, Dennis Dietrich, Martin Dufwenberg, Catherine Eckel, Christoph Engel, Ben Greiner, Werner Güth, Heike Hennig-Schmidt, Lisel Hintz, Astrid Hopfensitz, Norb Kerr, Vittoria Levati, Remi Maier-Rigaud, Ursula Rajtak, Reinhard Selten, Joroen van de Ven, three anonymous referees and the Max Planck library team. Financial support from the Swedish Agency for International Development Cooperation (SIDA) and from Vetenskapsrådet (The Swedish Research Council) is gratefully acknowledged.

* Corresponding author: Max Planck Institute, Kurt-Schumacher-Str. 10, D-53113 Bonn, Germany; E-mail: maierrigaud@ microeconomics.de, Tel: +49-(0)228/ 914160, Fax: + 49-(0)228/ 9141655.
} 


\section{Introduction}

The practice of excluding members of communities, groups and teams to enforce norm conformity and cooperation has been evidenced in almost all civilizations and known cultures (Gruter and Masters, 1986; Williams 2001). Ostracism ${ }^{1}$, the act of excluding, has been widely documented and analyzed in many disciplines. Indeed, regulating and sanctioning behavior by ostracizing noncontributing members can be found in animals (Goodall, 1986; Lancaster 1986), and humans (Wiessner, 2005; Kurzban and Leary, 2001; Williams et al., 2000; Boehm, 1999; Mahdi, 1986) alike. Ostracism has, however, not only been observed in animal groups, primitive cultures and ancient civilizations, but has also been observed in modern societies - for instance, with respect to strike-breakers or whistle-blowers, as well as to low performers in team production settings (see Durkheim, 1933; Gordon, 1975; Francis, 1985; Williams, 2001). There exist many economic contexts, such as team production or other social dilemma problems, where it is feasible to ostracize individuals for the lifetime of the project when monitoring and punishment are decentralized. Moreover, Gaspart and Seki (2003) provide an empirical example of a local fishery demonstrating elements of ostracism. In general, ostracism is the consequence of breaking an established rule or a social norm. In the former case, ostracism is normally enforced exogenously, while in the latter case ostracism is imposed endogenously according to self-established criteria.

The objective of this paper is to analyze the effects of ostracism using a controlled laboratory experiment. Our experimental design models situations, such as team work involving peers, when the latter have some influence upon team membership, a constellation that arises in particular in project teams within public administrative bodies, firms or in small-scale entrepreneurial activities, but also in local fisheries. More specifically, we investigate the effects of ostracism on contribution levels to a public good as well as on the overall welfare by applying a multi-period public good game with a partner matching design. Our experimental design provides the members of six-person groups with information on the contribution levels of the other five and with the possibility of casting a vote in order to exclude one member. A member is ostracized from the group if she obtains at least $50 \%$ of the votes. Excluded members no longer share any of the benefits of the public good and are also excluded from voting. In other words, ostracized members

\footnotetext{
${ }^{1}$ The word ostracism comes from the Greek ostrakismos, describing a practice originating in Athens as a political device instituted, probably by Cleisthenes in 508 B.C., as a constitutional safeguard for the Athenian democracy.
} 
are fully excluded from all future group activities. ${ }^{2}$ Although even a zero-contributing member does not directly reduce the other group members' payoffs, and in that respect is harmless to the group, we find that participants frequently ostracize the lowest contributor, thereby reducing the potential group productivity. A large fraction of voting activity and actual ostracism takes place during the first periods of the experiment. Remarkably, most of the remaining members usually converge towards full or almost full contribution, a situation that is sustained in most periods, although cooperation breaks down towards the end of the experiment.

Many different forms of punishment exist, and previous experiments have demonstrated how sanctions among peers work quite effectively in fostering cooperation in groups. Exclusion is a powerful instrument when other, direct forms of punishment (from pay cut to imprisonment), usually enforced by formally established institutions, are not available. Especially in contexts where group interaction acquires a social meaning, exclusion or the threat thereof can constitute a powerful deterrent against behavior that does not correspond to the social norm. The possibility of ostracism can take different forms: people can be excluded from ongoing or future projects, from the team or from other relationships that form a natural complement to work (such as lunch or social events). An example, often cited in the economics literature on punishment, is Francis (1985), where ostracism for "scabs" breaking strikes is discussed. ${ }^{3}$ Again, the existence of social relationships outside work reinforce the motivational effectiveness of exclusion mechanisms, and this is possibly one of the reasons for fostering social activities outside the workplace such as excursions, parties or sports tournaments.

In the following section we discuss the related literature. In section 3 we present the experimental design and procedures and in section 4 we derive predictions, first based on standard gametheoretic assumptions and second considering "social preferences". In section 5 the results and in section 6 the concluding remarks are presented.

\footnotetext{
Athenian citizens would cast a vote by writing on ostraca, shards of pottery, to remove for a period of ten years any person who threatened the harmony and tranquility of the body politic.

${ }_{2}^{2}$ Although it would be interesting to study cooperation in a more complex setting where ostracized members are reintegrated into the group, our design focuses on complete exclusion, a situation that resembles more closely project based team work, where exclusion will last at least for the lifetime of a particular project.

${ }^{3}$ Indeed, the workers that agreed to work during the mine strikes in the UK in the 1980s are still sanctioned today for their behaviour.
} 


\section{Related Literature}

Theoretical research on the voluntary provision of public goods indicates that individuals have incentives to free-ride, leading to an inefficient provision under voluntary contribution. ${ }^{4}$ In contrast to this, people do contribute to public goods both in experimental laboratories (e.g. Ledyard, 1995; and Zelmer, 2003) and in the field (Ostrom, 1990; Gaspart and Seki, 2003; Wiessner, 2005). Experimental results have, however, consistently shown that it is difficult to sustain high contribution levels over time (e.g. Isaac and Walker, 1988; Andreoni, 1988; Croson, 1996).

One explanation for these results is that a large fraction of the observed behavior can be characterized either as that of a free-rider or as that of a conditional cooperator, willing to cooperate only as long as she expects others to do so as well. The actual speed of the decline of contribution levels over time depends on the proportion of free-riders and conditional cooperators in the group (e.g. Keser and van Winden, 2000; Fischbacher et al., 2001). In that respect, Gunnthorsdottir et al. (2001) and Gächter and Thöni (2005) show that re-matching of participants according to previous contribution levels results in high and sustainable contributions in groups of highly cooperative participants, while contributions are low in groups of non-cooperative participants.

Several mechanisms aimed at sustaining cooperation have been explored experimentally. Two important issues related to these mechanisms concern the questions of what constitutes an unacceptably low contribution to the public good and which punishment device(s) is then to be used. ${ }^{5}$ The trigger for punishment can either be introduced exogenously by using a predetermined rule or endogenously, where each group member decides when punishment should take place. For instance, Galbiati and Vertova (2008) show that an exogenously imposed sanctioning rule, together with a minimum required contribution level, result in a positive effect on contribution levels. Guillén et al. (2007) design a step-level public good experiment with and without a centralized punishment institution, finding that even after punishment is removed, the contribution levels are maintained at a higher level than those observed in groups without any experience of institutionalized punishment. Croson et al. (2007) find that using an exogenous rule, which

\footnotetext{
${ }^{4}$ See Hirshleifer and Rasmusen (1989) for a theoretical discussion of ostracism as an effective tool for promoting cooperation in repeated finite and infinite prisoner's dilemma games.
} 
excluded the lowest contributor from the benefits of the public good, enhances cooperation in a variety of team production settings. Similarly, Swope (2002) finds an increase in contribution levels in most of his treatments when introducing an exogenous rule imposing a minimum contribution level.

However, there also exists a debate in the literature related to the possibility that exogenous mechanisms may hamper cooperation as they crowd out the intrinsic motivation to cooperate. For instance, Frey and Oberholzer-Gee (1997) and Fehr et al. (2002) show that positive incentives may undermine voluntary cooperation. Tyran and Feld (2006) compare the effect of introducing a law (either mild or severe) either exogenously or endogenously, where the latter is established by voting among group members to punish non-cooperators. The interesting finding is that the mild law, which left free-riding profitable, resulted in significantly higher contribution levels in the groups that endogenously voted for the mild law when compared to groups where the law was introduced exogenously. ${ }^{6}$

A frequently studied punishment device in laboratory public good experiments is direct monetary punishment of members, while other less commonly tested devices include, for example, disapproval and exclusion. ${ }^{7}$ A common feature of these types of sanctions is that the level of punishment and the decision on whether to punish are endogenously determined. Costly monetary punishment mechanisms have proven to increase contribution levels even if sanctions were costly also to the punisher (see for instance Bochet et al., 2006; Fehr and Gächter, 2000; Ostrom et al., 1992). Interestingly, once the cost of punishment is considered, the effect on overall welfare tends to be ambiguous. ${ }^{8}$ Non-monetary punishment, communicated through "disapproval points", was also found to increase cooperation, albeit to a lower and less persistent extent. ${ }^{9}$

\footnotetext{
${ }^{5}$ In addition to punishment, reward mechanisms have also been explored in a public good context, for instance by Sefton et al. (2007).

${ }^{6}$ For a similar effect on cooperation rates, albeit in a prisoner's dilemma context, see Apesteguia and Maier-Rigaud (2007).

${ }^{7}$ Exclusion presupposes that participants can be excluded from the public good in the future, which is the case for example in local public good and team production settings.

${ }^{8}$ See for instance Gächter et al. (2008) who suggest that the detrimental effects of costly punishment on welfare may be due to experiments that are too short to fully reveal the effects of punishment.

9 See Masclet et al. (2003). Carpenter et al. (2004a, 2004b) also find positive effects on contributions based on the display of "unhappy faces". See Noussair and Tucker (2005) for an analysis of the effects of combining monetary and non-monetary sanctions. See also Ostrom et al. (1992) for an early analysis in a common-pool resource context. See
} 
Kerr (1999) shows that the threat of ostracism can stimulate cooperation in social dilemmas. Similarly, Kerr et al. (2006) analyze the threat of exclusion on the relationship between cooperators and defectors based on previous findings indicating that defectors have a negative impact on the behavior of other group members, i.e. the phenomenon that defectors act as bad apples spoiling the whole barrel. ${ }^{10}$ The paper that is probably most closely related to ours is Cinyabuguma et al. (2005). They investigate exclusion based on majority voting in an innovative public good experiment, in which a lump sum cost is imposed on those members voting for ostracism if the member voted for is excluded during that period. The excluded members are then assigned to another public good experiment in which their endowment is halved. Their results show an almost maximal level of contribution to the public good among non-excluded members. Masclet (2003) designed a multi-period public good experiment, where each period consisted of two successive public good experiments, the first relating to production and the second to some social activity. After the first experiment, each participant could ostracize members for one period (only one vote was required for ostracism) from the second experiment, i.e. the social activity, either at no cost or at some cost depending on the treatment. In both cases he finds that contribution levels in the first experiment increase.

\section{Experimental design and procedures}

96 students were recruited from different departments at Bonn University, Germany, to participate in two experimental sessions of a computerized experiment, programmed in z-Tree (Fischbacher, 2007). The experiment consists of two treatments: (i) a linear public good experiment and (ii) a public good experiment with ostracism. Each one consisted of ten periods followed by an additional ten periods of the other treatment. Before each treatment, participants received information about the structure of that treatment only (see Appendix for instructions). We control for the order effect by running the experiment in both orders. Each session, which in our case corresponds to a specific ordering of the two treatments, involves eight groups with six participants each. Participants were randomly assigned to groups and stayed in the same groups throughout the experiment.

Apesteguia and Maier-Rigaud (2006) for a discussion of the difference between public goods and common-pool resources.

${ }^{10}$ See also Ouwerkerk et al. (2005). 
In each period, participants simultaneously choose how much to contribute to the public good out of an endowment of 10 tokens. 1 token was equal to 0.025 Euro. Participant $i$ 's payoff is calculated according to the following function

$$
\pi_{i}=10-g_{i}+0.4 \sum_{i=1}^{6} g_{i}
$$

where $g$ is the contribution to the public good. With this payoff function, individuals have incentives to free-ride, as the marginal private return from contribution (0.4) is smaller than the marginal cost (1). The choice of these parameter values ensures that the social optimum is to invest fully in the public good, while the individuals' payoff-maximizing choice is to invest nothing.

In the ostracism treatment, there is a second stage in each period (the first stage remaining the standard public good experiment). First, each member is informed about the contribution levels of the other members (see the Appendix for a screenshot of the information provided). Each member could then decide either to cast a vote for ostracizing another member or to refrain from voting. The contribution levels by the other members are shown in randomized order on the screen and thus it is not possible to track the contribution by other members over time. This design feature closely follows the approach by Fehr and Gächter (2000) in their treatment on monetary punishment in a partner design. ${ }^{11}$ This allows us to closely compare our results with their results as well as with other papers that have used their design. After all members had made their voting decisions, each member was informed about the total number of votes she and other members received. The minimum number of votes required for ostracism was at least $50 \%$ of the votes from the remaining members in that specific period, i.e. three if the group consisted of five or six members, two if the group consisted of three or four members and one when there were only two remaining members. Ostracized members continue to receive 10 tokens for all remaining periods, but they neither gain any income from the public good nor are they allowed to vote. The direct effect of ostracizing a member is that the group size decreases. Since the marginal benefit from the

\footnotetext{
${ }^{11}$ A more detailed description on the information provided to their participants can be found on page 7 in the working paper version of their published paper (Fehr and Gächter, 1999).
} 
public good is set to 0.4 , and is independent of the size of the group, the decision to ostracize a member always reduces the potential maximum contribution to the public good.

While our experiment has 10 periods with one of the treatments followed by 10 periods of the other treatment, Cinyabuguma et al. (2005) have two different sessions; (i) 15 periods of a standard public good experiment followed by 15 periods of an ostracism treatment and (ii) 15 periods of an ostracism treatment followed by another 15 periods of an ostracism treatment. In both experiments there is a constant coefficient on the returns from the public good, instead of, for example, a coefficient that is inversely proportional to the number of group members. However, our coefficient is twice as large, 0.4 versus 0.2 . This partly compensates for the fact that we have a smaller initial group size, 6 participants instead of 15 participants. The maximal earning per participant in a period is 24 and 30 respectively. Thus, each of the remaining members loses up to 4 units per period per ostracized member in our design while it is only 2 in Cinyabuguma et al. (2005). Another difference relates to the treatment of the ostracized member. In our design, ostracized members are excluded from taking part in the experiment and thus only receive the endowment during the remaining periods of the experiment, whereas in their design members who have been ostracized are reallocated to a new group of likewise ostracized members. Our design thus analyzes the cooperation enhancing effects of exclusion in a simple design that mirrors real life situations (in particular team production settings) more closely, as excluded members no longer participate in further exchanges. More importantly, in the design by Cinyabuguma et al. (2005) the endowment is cut in half and contributions to the public good only increase overall welfare when the group has at least 6 members, a number that is never achieved. As a consequence, the earnings of ostracized members were only half of their original endowment, as it was never profitable to contribute to the public good. ${ }^{12}$ Furthermore, in our design there was no cost of voting, while in Cinyabuguma et al. (2005) the cost was $2.5 \%$ of the initial endowment if the participant they voted for was ostracized. ${ }^{13}$ On one hand we may expect participants to contribute less in our design since both the cost of ostracizing a member is higher in our design and the cost to a single member of being ostracized is lower. On the other hand there is no cost per $s e$ of voting in our design. In light of these factors, we expect lower contribution levels in our case

\footnotetext{
${ }^{12}$ In addition, participants in Cinyabuguma et al. (2005) were shown the earnings of both excluded and non-excluded members of the initial group rendering the cost of exclusion more salient.
} 
compared to Cinyabuguma et al. (2005).

\section{Predictions}

Despite the possibility of exclusion, which in some contexts may lead to cooperative equilibria (see e.g. the theoretical contribution in Hirshleifer and Rasmusen, 1989), the equilibria computed under standard payoff maximizing assumptions are characterized by zero contribution throughout our game. It is immediately evident that in the last period all players remaining in the game contribute zero, so that the payoff is 10 for all players (including the ostracized ones). By backwards induction, cooperation unravels from the end until the beginning of the game and the only subgame perfect Nash equilibrium is zero contribution in every period. Any configuration of votes and group sizes can be part of an equilibrium, that is, there exist a multiplicity of equilibria with different voting behavior and corresponding different group sizes throughout the game.

If, for whatever reason, positive contributions cannot be excluded - for instance by mistake ostracizing group members can be costly. If we consider the possibility of mistakes (e.g. the "trembling hand" refinement of the Nash equilibrium, Selten, 1975) then players would choose not to vote to ostracize anyone. In fact, notice that ostracizing a member who is going to contribute only 1 unit throughout all remaining periods will result in giving up 0.4 payoff for each of the remaining group members. Under standard assumptions, no contributions to the public good occur. Furthermore, if there is a positive, albeit small, probability of mistakes consisting in non-zero contributions, then there will also be no voting to exclude other members.

Laboratory evidence of contributing and punishing behavior resulting in a subsequent increase in overall cooperation has led to theoretical research in order to accommodate these findings. Building upon Rabin (1993), Charness and Rabin (2002) introduce positive and negative reciprocity along with "social welfare" consideration. ${ }^{14}$ Bolton and Ockenfels (2000) and Fehr and Schmidt (1999) emphasize inequality (or, more broadly, "inequity”) aversion, i.e. that individuals tend to prefer equality in outcomes, so that they return cooperation in order to avoid favorable

\footnotetext{
${ }^{13}$ In addition, the difference regarding the subject pool, i.e. US students in the case of Cinyabuguma et al. (2005) and German students in our case, has to be mentioned.

${ }^{14}$ Another line is based on learning concepts (see in particular McKelvey and Palfrey, 1995).
} 
inequality in payoffs but are also willing to punish free riders (who would otherwise enjoy the highest payoffs).

What these models do not suggest is which norm group members should follow in order to avoid exclusion. Of course, full contribution can be appealing, but while the threat of ostracism may reinforce such an outcome, the actual exclusion of a member reduces the potential maximum production in the remaining periods. While social preference models assume that some players will have non-selfish motivations, they do not exclude the presence of purely selfish players. The interaction between different types of participants may lead to different outcomes depending on the features of the game. Fehr and Gächter (2000) found that the (exerted) threat of punishment leads to high contributions until the last period. In their design, the cost of being punished remains constant. In our experiment, however, this is not the case, as being ostracized is more costly (assuming some cooperation) the more periods of the experiment are left. Hence, it is possible that selfish players adjust contribution levels upwards (when escaping ostracism but observing others being ostracized) but also that "end-game effects" (Selten and Stoecker, 1986) appear and contribution levels fall in the last periods. In summary, all models based on "social preferences" or "other-regarding" preferences - in which non-selfish individuals exist along with selfish ones tend towards predicting the exclusion of low contributors and the possible positive effects on contribution levels in subsequent periods by remaining group members until "end-game" effects emerge. The aim of this paper is not to assess the validity of any particular functional form of such models, and it should also be noted that these models do not engage the speed of adjustment and the contribution level deemed to be acceptable by non-selfish players. Full contribution, however, could constitute a focal point in terms of building up a specific and easily communicated norm that can also be sustained by coherent voting behavior. ${ }^{15}$

\section{Results}

In our discussion of the results, we begin by presenting the general behavioral response of introducing ostracism, followed by a more detailed analysis of contributions when ostracism is possible as well as of voting behavior. Figure 1 depicts the temporal patterns of average

\footnotetext{
${ }^{15}$ That is, voting to exclude low contributors until contributions reach a maximum level. One should take into account that field situations usually involve less easily quantifiable contribution levels by group members, so that the enforcement of specific norms may be more difficult.
} 
contributions. Each session consists of two treatments both lasting 10 periods. The treatments are either run in the order of 10 periods without ostracism followed by 10 periods with ostracism or in the reverse order. Thus, contributions shown for periods 1-10 refer to averages when the standard public game was conducted as the first treatment in a session, while contributions for periods 1120 indicate when the game was the last treatment. There are three distinct lines depicted in Figure 1. The solid line shows the pattern of average contribution levels in the standard public good treatment, which we identify as "No ostracism" in the figure. Average contributions decrease monotonically over time independently of whether "no ostracism" was the first or last treatment in a session. The other two lines show contributions in the ostracism treatment. The dashed line represents average contributions by the remaining members in a group in the ostracism treatment, which is calculated as the ratio of total contributions of the group members and the remaining members of the group. This is labeled "Net effect - Ostracism". The third line, which is dotted, is identified as "Gross effect - Ostracism" and shows the average contributions based on the original group size, which is calculated as the ratio of total contributions of the group members and the original group size of 6 members. Thus, the latter measure considers the loss in contribution to the public good at "societal" level.

\section{>> FIGURE 1}

We find a sharp monotonic decline in average contributions for the standard public good experiment. Average contributions are similar to those observed in most multi-period public good experiments (e.g. Zelmer, 2003; Ledyard, 1995) and decline from slightly above 50\% of the endowment in the first period of the treatment to approximately $30 \%$ in the final period if given as the first treatment, and to approximately $10 \%$ if given as the last treatment of a session. A Wilcoxon rank-sum test is applied to test the null hypothesis of no order effect in the standard public good experiment, i.e. that the average contributions at group level for a given period within the standard public good experiment - either conducted as the first or the last treatment in the session - are from the same distribution (see Siegel and Castellan, 1988). First, we test whether average contributions at group level in the standard public good game in period 1 of the entire experiment (when the standard public good game was the first treatment) and contributions in the standard public good game in period 11 of the entire experiment (when the standard public good game was the second treatment) have the same distribution. Then we test whether the contribution 
levels in the standard public good game in period 2 of the entire experiment (when the standard public good game was the second treatment) and those in the standard public good game in period 12 of the entire experiment (when the standard public good game was the second treatment) have the same distribution and so forth for the remaining 8 periods. We can only reject the null hypothesis of no order effect at 5\% significance level in the last period, which indicates an endgame effect (e.g. Selten and Stoecker, 1986).

In the ostracism treatment, the net average contributions at group level, i.e. average contributions based on non-ostracized members, increased to around $85 \%$ of maximum contributions after the first periods when ostracism was included in the first treatment of a session, while contributions were around $80 \%$ when given as the last treatment. In both cases we observe an end of the treatment effect, but the effect is stronger when ostracism was given as the last treatment of a session. A similar relationship is found when looking at gross average contributions at group level, i.e. average when considering the original group size of 6 members, with averages around $70 \%$ and $60 \%$ when given as first and last treatment in a session, respectively. Of course, an end treatment effect is found here and it is stronger when it is the last period of the entire session, which again indicates an end-game effect. It is noteworthy that even when we consider average contributions based on the original sample size, they are higher than those in the standard public good treatment. However, the contributions in our experiment are lower than those reported in Cinyabuguma et al. (2005), where the net contribution levels oscillated around $90 \%$. A possible explanation for this is that the threat of ostracism is weaker in our case since it is more costly for remaining members to ostracize a participant in terms of the potential loss of future contributions, while the cost of being ostracized is lower compared to Cinyabuguma et al. (2005) since the endowment is not reduced in our case. Thus, the results of Cinyabuguma et al. (2005) and ours are consistent with each other. The afore-mentioned differences in the design of the experiment may also explain why we observe an earlier end-game effect in our experiment as well as a sharper decline in contributions in the last periods compared to Cinyabuguma et al. (2005). We conduct a Wilcoxon rank-sum test to test the null hypothesis of no order effect, i.e. that average contributions at group level for a given period within the ostracism treatment either conducted as the first or the last treatment in the session are from the same distribution, in the same way as we did for the standard public good experiment. We can only reject this hypothesis at 5\% significance level for the last period in an ostracism treatment (both for gross and net contributions), i.e. when tested the 
last period of the treatment was given as the first or last treatment in a session. This can again be seen as an end-effect.

In a Wilcoxon rank-sum test, we test the null hypothesis of no difference in average contributions between the non-ostracism and ostracism treatments at a given period in the entire experiment when the average contributions in the ostracism treatment is based on the remaining group members, i.e. the average net contributions. Thus, we begin to test the null hypothesis of no difference in average contributions at group level between non-ostracism and ostracism treatment at period 1 of the entire session, and then we conduct the same test for the remaining 19 periods. The null hypothesis can be rejected for all periods at a 5\% significance level except for the first two periods in each treatment, i.e. period 1 and 2 and period 11 and 12, as well as for the last period of the entire session, i.e. period 20. A similar test based on the original sample size of 6 members shows similar results, but also the periods 10,13 and 19 cannot be rejected. Since there is no cost of ostracizing a member, the earnings are directly rescaled from the contribution levels. Thus, from a welfare perspective, average earnings are higher in the groups where ostracism is possible.

In Figure 2, we show the average number of ostracized members in a group at the end of each period. On average, slightly more members were ostracized when the ostracism treatment was given as the last treatment in a session rather than the first treatment. This difference may partly be explained by substantial ostracism in one of the groups in the last treatment, where all members had been ostracized by the last period of the treatment. Taking all ostracism treatments together, 9 members (4 in the first and 5 in the last treatment of a session) were ostracized out of potentially 16 members (since we have 16 groups) in the first period of ostracism treatment, followed by 7 in the second period of the treatment. During the next six periods, 9 members were ostracized while the number increased again and 4 members were ostracized in the ninth period of the treatment. In each period of the ostracism treatment, we tested the null hypothesis that the number of members ostracized in a group is independent of whether the ostracism treatment was the first or the last treatment in a session using the Wilcoxon rank-sum test, i.e. we test for treatment order effects using the same stratagem as described above. We cannot reject the null hypothesis at a $5 \%$ significance level in any of the periods. 


\section{>> FIGURE 2}

In Figure 3, we show the proportion of group members (among those not already being ostracized) casting a vote for another group member to be ostracized. In the figure, we again separate out whether the ostracism treatment was the first or the last treatment of a session. Voting behavior at the start of both ostracism treatments was active with approximately two-thirds of the members casting a vote in the first period, followed by a sharp decline to about $20 \%$ when ostracism was in the first part of a session. The proportion of votes cast was much higher when ostracism was the last treatment of a session and this is at least partly explained by lower contributions to the public good when ostracism is the last rather than the first treatment of a session. Moreover, there was a sharp increase in the proportion of votes cast in the last periods when ostracism was the last treatment of a session, which corresponds to the end-game effect as shown in Figure 1. In each period of the ostracism treatment we tested the null hypothesis of no order effect with respect to the fraction of participants that cast votes to ostracize another member using the Wilcoxon ranksum test. We cannot reject the hypothesis of no order effect at a 5\% significance level in any of the pair-wise tested periods.

\section{>> FIGURE 3}

Finally we conduct two regressions. In the first regression, we investigate the determinants of the number of votes received out of total votes, which is calculated as the ratio of the number of votes cast by others in the group for a specific member of the group and the number of remaining group members except the member for whom votes are cast (since a member cannot cast a vote for herself) in percentage. In a tobit regression analysis, we analyze how the others' average contribution, the member's absolute positive deviation from others' average contribution and the member's absolute negative deviation from others' average contribution explain the relative amount of votes cast for a specific member. Table 1 shows, as expected, that absolute negative deviations from others' average contribution significantly increases the proportion of votes received at $1 \%$ level. In the second parametric analysis, we use a probit regression to analyze whether or not a member was ostracized using the same explanatory variables as in the first regression. The results are similar to the first regression, i.e. negative deviations from others' 
average contribution have a significant positive impact at $1 \%$ level on the probability of being ostracized. In both regressions, we include period and group dummy variables.

\section{$\gg>$ TABLE 1}

\section{Conclusion}

In standard public good experiments, the average contribution level typically declines over time and converges to around $10-15 \%$ of the endowment in the last period. The experimental literature shows various instances in which sanctions positively affect contributions. Cooperation increases especially when sanctions are endogenous, i.e. their existence and/or implementation depends on decisions by group members. In particular, this is also the case when peer sanctioning consists of the possibility of exclusion.

Our paper contributes to the literature of endogenous sanctions by allowing group members to exclude others based on strict majority voting. The effect of ostracism as a sanctioning device is that the group size is reduced, undermining the potential efficiency of the group in all future periods. This is in contrast to various other forms of punishments tested in the literature which entail a direct monetary effect in that period, without affecting potential maximum overall welfare from the public good in future periods.

We find that group members do tend to vote to ostracize other members and, unsurprisingly, these votes go mainly to low contributors. In fact, the ostracized members were always the lowest contributors. Despite the potential negative impact on maximum overall welfare, such behavior is effective in fostering cooperation among the remaining group members. As a result, the overall contribution level is substantially and significantly higher in the public good game with ostracism among those not ostracized as opposed to the standard public good game. Unsurprisingly this cooperation-enhancing effect vanishes as the game approaches the end, when the adverse consequences of being ostracized become less significant. This suggests that mechanisms based on ostracism are effective in the presence of sufficiently large - albeit not "infinite" - time horizons. Our experimental results corroborate the findings from experiments on sanctioning and exclusion 
as well as those from field studies on the effectiveness of ostracism as a regulatory instrument to enforce norm conformity and cooperation in groups.

There is scope for extending this research further in the direction of exploring how ostracism can foster cooperation, both with reference to the length of time a participant is ostracized and with respect to the information feed-back of previous contribution levels. Information on contributions and votes cast could be given throughout the whole session. This would allow reputation to play a more prominent role and would possibly also allow more gradual "warnings" instead of direct exclusion. 


\section{References}

Andreoni, J., 1988. Why free ride? Strategies and learning in public good experiments. Journal of Public Economics 37, 291-304.

Apesteguia, J., Maier-Rigaud, F. P., 2006. The role of rivalry: Public goods versus common-pool resources. Journal of Conflict Resolution 50, 646-663.

Apesteguia, J., Maier-Rigaud, F. P., 2007. The role of choice in social dilemma experiments. Working Paper, Department of Economics, University of Bonn.

Bochet, O., Page, T., Putterman, L., 2006. Communication and punishment in voluntary contribution experiments. Journal of Economic Behavior and Organization 60, 11-26.

Boehm, C., 1999. Hierarchy in the Forest: The Evolution of Egalitarian Behavior. Harvard University Press: Cambridge.

Bolton, G.E., Ockenfels, A., 2000. A theory of equity, reciprocity and competition. American Economic Review 100, 166-193.

Carpenter, J. P., Daniere, A. G., Takahashi, L.M., 2004a. Cooperation, trust, and social capital in southeast asian urban slums. Journal of Economic Behavior and Organization 55, 533-551.

Carpenter, J. P., Daniere, A. G., Takahashi, L.M., 2004b. Social capital and trust in south-east asian cities. Urban Studies 41, 853-874.

Charness, G., Rabin, M., 2002. Understanding social preferences with simple tests. Quarterly Journal of Economics 117, 817-869.

Cinyabuguma, M., Page, T., Putterman, L., 2005. Cooperation under the threat of expulsion in a public goods experiment. Journal of Public Economics 89, 1421-1435.

Croson, R., 1996. Partners and strangers revisited. Economics Letters 53, 25-32.

Croson, R., Fatás, E., Neugebauer, T., 2007. Excludability and contribution: A laboratory study in team production. Working Paper, Wharton School, University of Pennsylvania.

Durkheim, E., 1933. The Division of Labor in Society. Free Press: New York.

Fehr, E., Gächter, S., 1999. Cooperation and punishment in public goods experiments. Working paper 10 at Institute for Empirical Research, University of Zurich.

Fehr, E., Gächter, S., 2000. Cooperation and punishment in public goods experiments. American Economic Review 90, 980-994.

Fehr, E., Fischbacher, U., Gächter, S., 2002. Strong reciprocity, human cooperation and the enforcement of social norms. Human Nature 13, 1-25. 
Fehr, E., Schmidt, K.M., 1999. A theory of fairness, competition and cooperation. Quarterly Journal of Economics 114, 817-868.

Fischbacher, U., 2007. z-Tree: Zürich toolbox for readymade economic experiments. Experimental Economics 10, 171-178.

Fischbacher, U., Gächter, S., Fehr, E., 2001. Are people conditionally cooperative? Evidence from a public good experiment. Economic Letters 71, 397-404.

Francis, H., 1985. The law, oral tradition and the mining community. Journal of Law and Society 12, 267-271.

Frey, B., Oberholzer-Gee, F., 1997. The cost of price incentives: An empirical analysis of motivation crowding out. American Economic Review 87, 746-755.

Gächter, S., Thöni, C., 2005. Social learning and voluntary cooperation among like-minded people. Journal of the European Economic Association 3, 303-314.

Gächter, S., Renner, E., Sefton, M., 2008. The long-run benefits of punishment. Science 322, 1510 .

Galbiati R., Vertova, P., 2008. Obligations and cooperative behaviour in public goods game. Games and Economic Behavior 64, 146-170.

Gaspart, F., Seki, E., 2003. Cooperation, status seeking and competitive behaviour: Theory and evidence. Journal of Economic Behavior and Organization 51, 51-77.

Goodall, J., 1986. Social rejection, exclusion, and shunning among the Gombe chimpanzees. Ethnology and Sociobiology 7, 227-236.

Gordon, M. A., 1975. The labor boycott in New York City, 1880-1886. Labor History 16, $184-$ 229.

Gruter, M., Masters, R. D., 1986. Ostracism as a social and biological phenomenon: An introduction. Ethnology and Sociobiology 7, 149-158.

Guillén, P., Schwieren, C., Staffiero, G., 2007. Why feed the Leviathan? Public Choice 30, 115128.

Gunnthorsdottir, A., Houser, D., McCabe, K. 2001. Dispositions, history and contributions in public goods experiments. Journal of Economic Behavior and Organization 62, 304-315.

Hirshleifer, D., Rasmusen, E., 1989. Cooperation in a repeated prisoners' dilemma with ostracism. Journal of Economic Behavior and Organization 12, 87-106. 
Isaac R., Walker, J., 1988. Group size effects in public group provision: The voluntary contribution mechanism. Quarterly Journal of Economics 103, 179-99.

Kerr, N. L., 1999. Annonymity and social control in social dilemmas. In: M. Foddy et al. (Eds.). Resolving social dilemmas (pp. 103-119). Psychology Press: Philadelphia, PA.

Kerr, N. L., Rumble, A. C., Park, E. S., Ouwerkerk, J. W., Parks, C. D., Gallucci, M., van Lange, P. A. M., 2006. How many bad apples does it take to spoil the whole barrel? Social exclusion and toleration for bad apples. Journal of Experimental Social Psychology 405, 603-613.

Keser, C., van Winden, F., 2000. Conditional cooperation and voluntary contributions to public goods. Scandinavian Journal of Economics 102, 23-39.

Kurzban, R., Leary, M. R., 2001. Evolutionary origins of stigmatization: The functions of social exclusion. Psychological Bulletin 127, 187-208.

Lancaster, J. B., 1986. Primate social behavior and ostracism. Ethnology and Sociobiology 7, 215225.

Ledyard, J., 1995. Public goods: A survey of experimental research. In: Roth, A. and Kagel, J. (Eds.). Handbook of Experimental Economics. Princeton University Press: Princeton.

Mahdi, N. Q., 1986. Pukhtunwali: Ostracism and honor among the Pathan Hill tribes. Ethnology and Sociobiology 7, 295-304.

Masclet, D., 2003. Ostracism in work teams: A public good experiment. International Journal of Manpower 24, 867-887.

Masclet, D., Noussair, C., Tucker, S., Villeval, M.-C., 2003. Monetary and non-monetary punishment in the voluntary contributions mechanism. American Economic Review 93, 366-380.

McKelvey, R.D., Palfrey, T.R., 1995. Quantal response equilibria for normal form games. Games and Economic Behavior 10, 6-38.

Noussair, C., Tucker, S., 2005. Combining monetary and social sanctions to promote cooperation. Economic Inquiry 43, 649-660.

Ostrom, E., 1990. Governing the Commons. The Evolution of Institutions for Collective Action. Cambridge University Press: Cambridge.

Ostrom, E., Walker, J., Gardner, R., 1992. Covenants with and without a sword: Self-governance is possible. American Political Science Journal 86, 404-417.

Ouwerkerk, J.W., van Lange, P.A.M., Gallucci, M., Kerr, N.L., 2005. Avoiding the social death penalty: Ostracism and cooperation in social dilemmas. In: Williams, K.D., Forgas, J.P., von Hippel, W. (Eds.). The Social Outcast: Ostracism, Social Exclusion, Rejection, and Bullying. The Psychology Press: New York, 539-558. 
Rabin, M., 1993. Incorporating fairness into game theory and economics. American Economic Review 83, 1281-1302.

Sefton, M., Shupp, R., Walker , J., 2007. The effect of rewards and sanctions in provision of public goods. Economic Inquiry 45, 671-690.

Selten, R., 1975. Re-examination of the perfectness concept for equilibrium in extensive games. International Journal of Game Theory 4, 22-25.

Selten, R., Stoecker, R., 1986. End behavior in sequences of finite prisoner dilemma supergames. Journal of Economic Behavior and Organization 7, 47-70.

Siegel, S., Castellan Jr., N. J., 1988. Nonparametric Statistics for the Behavioral Sciences, McGraw Hill: New York.

Swope, K., 2002. An experimental investigation of excludable public goods. Experimental Economics 5, 209-222.

Tyran, J.-R., Feld, L.P., 2006. Achieving compliance when legal sanctions are non-deterrent. Scandinavian Journal of Economics 108, 135-156

Wiessner, P., 2005. Norm enforcement among Ju/ hoansi bushmen. A case of strong reciprocity? Human Nature 16, 115-145.

Williams, K. D., 2001. Ostracism: The power of silence. Guilford Publications: New York.

Williams, K. D., Cheung, C. K. T., Choi, W., 2000. Cyberostracism: Effects of being ignored over the internet. Journal of Personality and Social Psychology 79, 748-762.

Zelmer, J., 2003. Linear public goods experiments: A meta-analysis. Experimental Economics 6, 299-310. 
Figure 1. Average contribution levels by treatment.

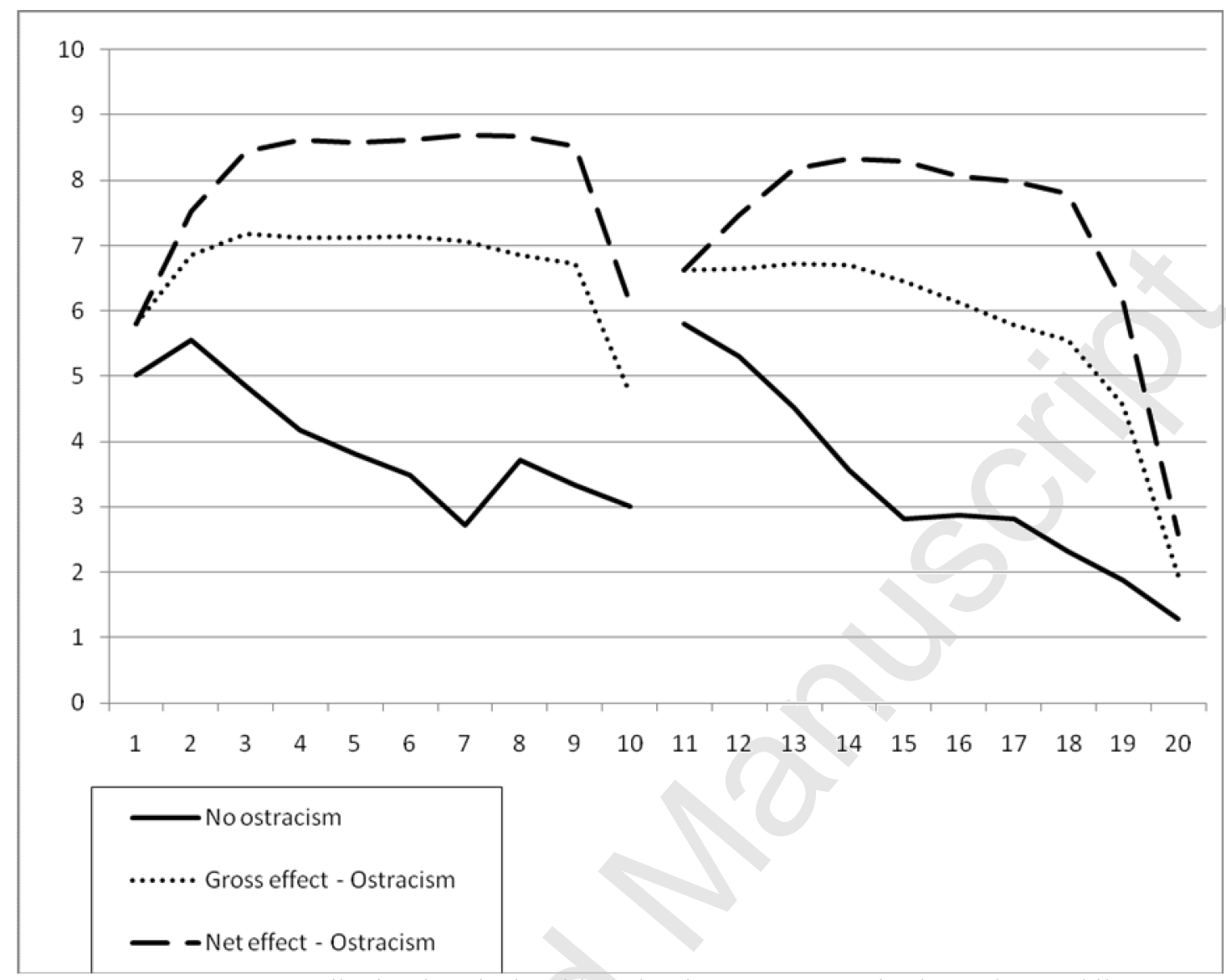

Note. Average gross contribution is calculated based only on non-ostracized members, while average net contribution is based on the original sample size. 
Figure 2. Average number of ostracized subjects at group level at the end of a period.

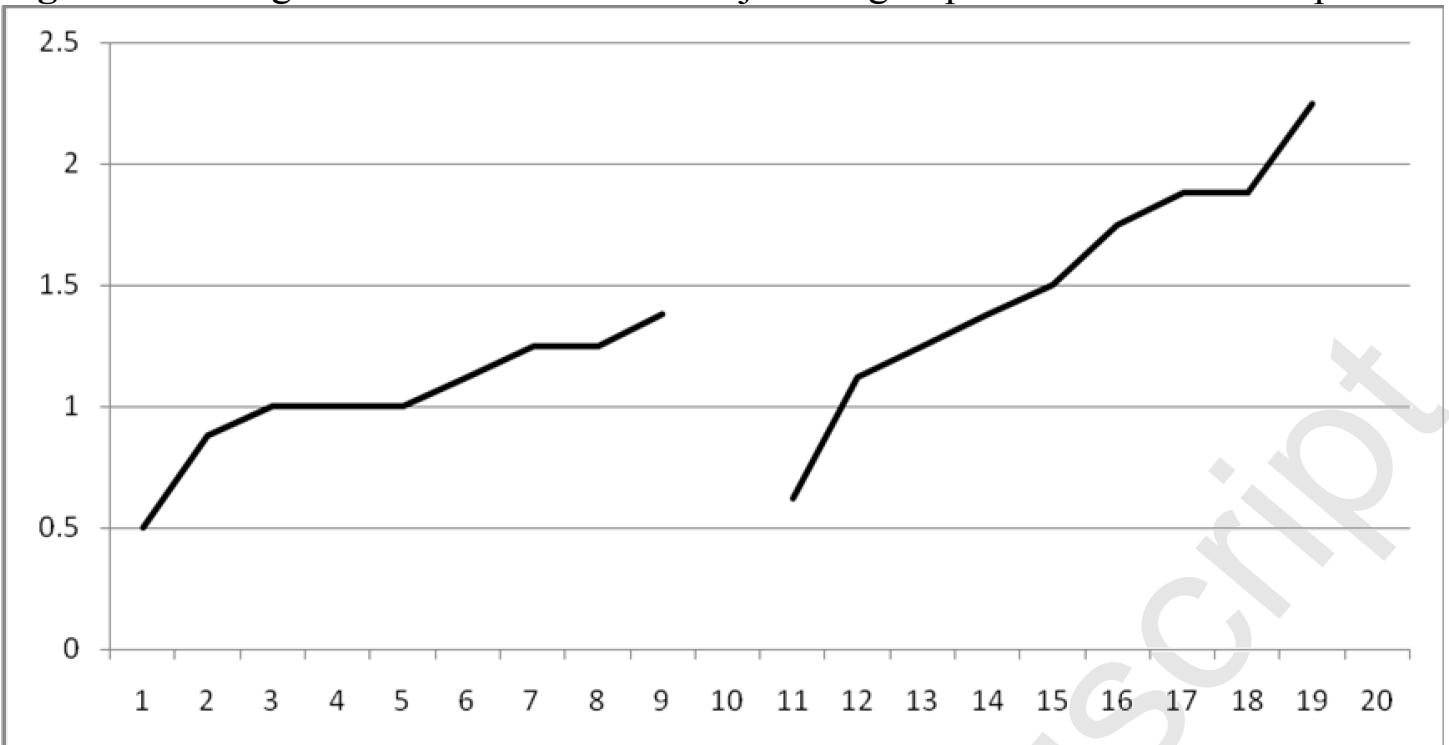

Note. Period 1-9 show ostracism in the first session, while period 11-19 show it when it is the last session. 
Figure 3. Average proportion of non-ostracized members voting in each period.

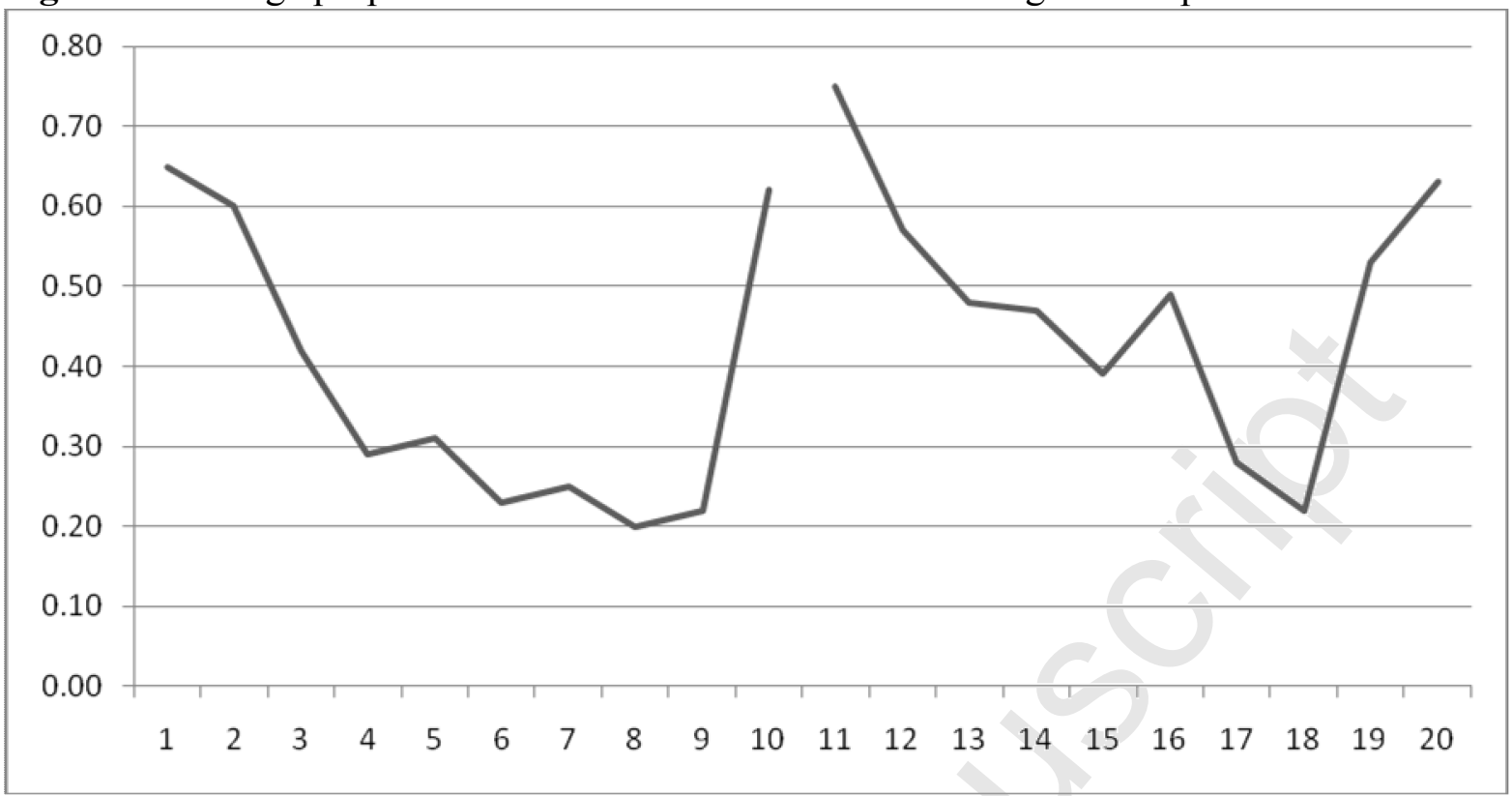


Table 1. Regression analysis.

Dependent variable Number of votes

$\begin{array}{ll}\text { as a fraction of } & \text { Whether the } \\ \text { total votes (in } & \text { subject was } \\ \text { percentage) } & \text { ostracized } \\ \text { (Tobit) } & \text { (Probit) }\end{array}$

\begin{tabular}{lcccc}
\hline & $\begin{array}{l}\text { Marginal } \\
\text { effects }\end{array}$ & $\begin{array}{l}\text { Standard } \\
\text { error }\end{array}$ & $\begin{array}{l}\text { Marginal } \\
\text { effects }\end{array}$ & $\begin{array}{l}\text { Standard } \\
\text { error }\end{array}$ \\
\hline $\begin{array}{l}\text { Others' average } \\
\text { contribution }\end{array}$ & $-1.070^{*}$ & 0.554 & -0.002 & 0.002 \\
$\begin{array}{l}\text { Absolute positive } \\
\text { deviation }\end{array}$ & 0.172 & 0.525 & -0.000 & 0.002 \\
$\begin{array}{l}\text { Absolute negative } \\
\text { deviation }\end{array}$ & $4.425 * *$ & 0.402 & $0.008^{*}$ & 0.004 \\
\hline $\begin{array}{l}\text { Pseudo R2 } \\
\text { Number of }\end{array}$ & & 0.09 & & 0.51 \\
observations & & 709 & & 638 \\
\hline
\end{tabular}

Note. ${ }^{* *}$ denotes significance at $1 \%$ level and * at $10 \%$ level. The last period in the ostracism treatment is not included in the analyses due to end-game effects. Group dummies and period dummies have been included in the regressions to control for group fixed effects, but omitted in the presentation above. 